\title{
FOREST PRODUCTS
}

\section{VISION:}

THE U.S. FOREST, WOOD AND PAPER INDUSTRY IN 2020 WILL BE A CLEAR GLOBAL LEADER IN PRDVIDING SAFE AND ESSENTIAL PRODUCTS IN HARMONY WITH THE ENVIRONMENT AND WILL BE A SUSTAINABLE CONTRIBUTOR TO OUR NATION'S EGONOMY AND TO THE QUALITY OF LIFE OF ITS CITIZENS

\section{FROM AGENDA 2020:} A TECHNOLOGY YSION AND RESEARCH AGENDA FOR AMERICA'S FOREST, WOOD AND PAPER IWDUSTRY AMERICAN FOREST \& PAPER ASSOCIATION

\section{INDUSTRY OF THE FUTURE}
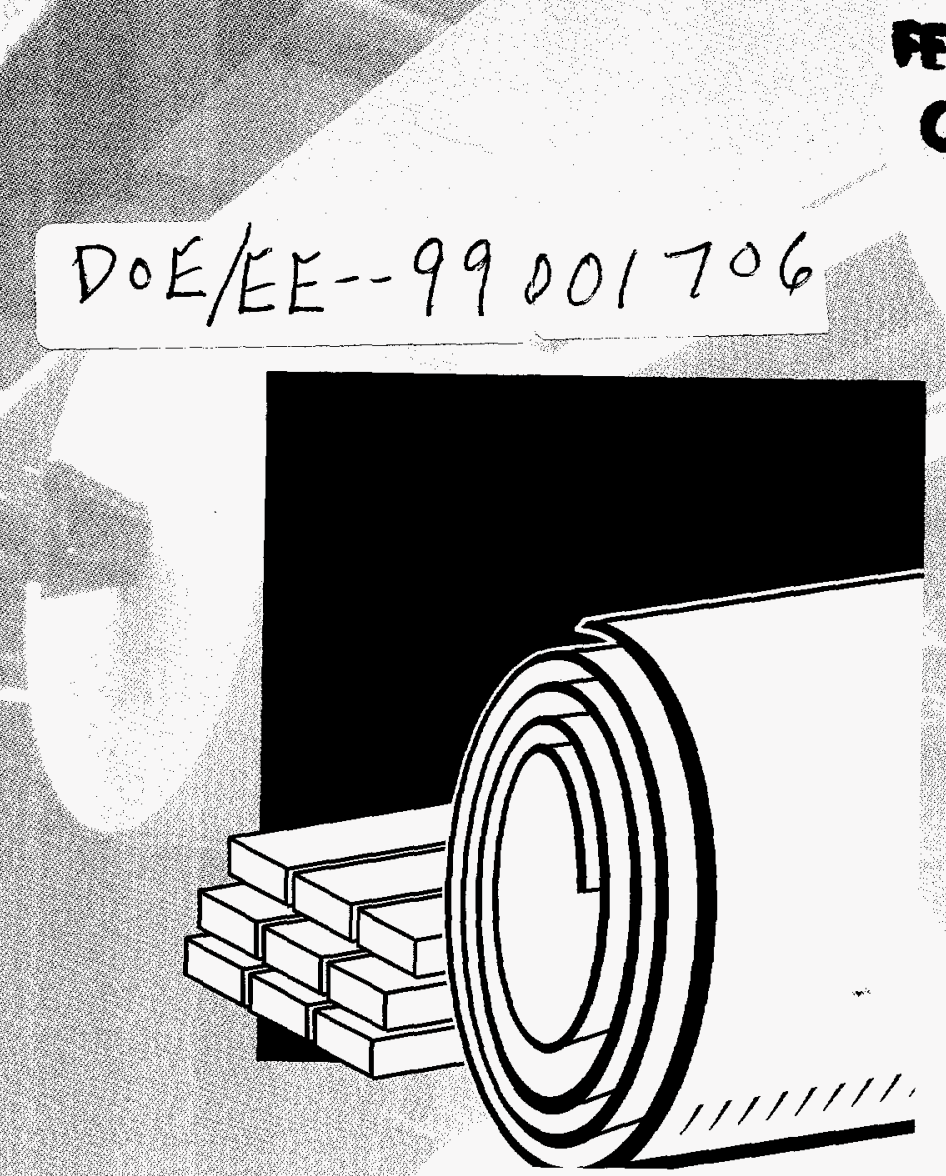

Building a sustainable technology

advantage for America's forest

products industry

DOE/EE- 99001706

\section{O8TI}

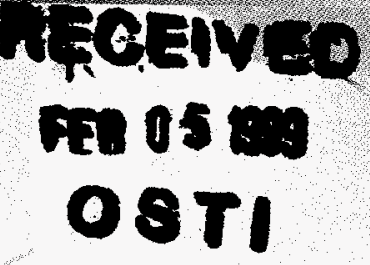




\section{THE VISION}

\section{Providing a framework}

\section{for cooperative $R \& D$}

The U.S. forest, wood, and paper industry ranks as one of the most competitive forest products industries in the world. With annual shipments valued at nearly $\$ 267$ billion, it employs over 1.3 million people and is currently among the top 10 manufacturing employers in 46 out of 50 states. Retaining this leadership position will depend largely on the industry's success in developing and using advanced technologies. These technologies will enable manufacturing plants and forestry enterprises to maximize energy and materials efficiency and reduce waste and emissions, while producing high-quality, competitively priced wood and paper products.

In a unique partnership, leaders in the forest products industry have teamed with the U.S. Department of Energy's Office of Industrial Technologies (OIT) to encourage cooperative research efforts that will help position the U.S. forest products industry for continuing prosperity while advancing national energy efficiency and environmental goals.

\section{Partnerships for the Future}

Coordinated by the American Forest and Paper Association (AF\&PA), industry leaders produced a vision that establishes longterm goals and broad research priorities for the industry in response to key market, business, and environmental drivers. The vision document, Agenda 2020: A Technology Vision and Research Agenda for America's Forest, Wood and Paper Industry, states that by the year 2020 the industry "will be the clear global leader in providing safe and essential products in harmony with the environment and will be a sustainable contributor to our nation's economy and to the quality of life of its citizens."

The Agenda 2020 Compact for the Forest Products Industry, signed by the Secretary of Energy and the AF\&PA soon after the vision's publication, laid the groundwork for collaborative research efforts. The vision indentifies six technology areas as high-priority and also suitable for cooperative research: 1) Sustainable Forest Management, 2) Environmental Performance, 3) Energy Performance, 4) Improved Capital Effectiveness, 5) Recycling, and 6) Sensors and Control.

\section{THE ROADMAP}

\section{Defining technology priorities and performance targets}

Industry-led task groups, organized in cooperation with the AF\&PA, have been established for each of the six technology areas identified in Agenda 2020. Comprised of representatives from academia, government, National Laboratories, and a broad cross-section of the industry, the six task groups are responsible for implementing the Forest Products Industries of the Future process. The groups define specific research needs, issue requests for proposals, and evaluate and recommend proposals for funding.

The task groups started by creating a series of research pathways, referred to collectively as the Implementation Plan, for achieving specific performance goals. Each research pathway describes the link to Agenda 2020, ongoing and future research needs within the technology area, and desired research products and results. The pathways are reviewed annually and provide the basis for competitive solicitations for research proposals. OIT selectively co-funds projects that contribute to its mission of improving energy efficiency and preventing pollution. As of 1998, close to 70 industry cost-shared research projects have been funded by OIT through the Forest Products Industries of the Future process.

In order to serve as an accurate and effective roadmap, the Forest Products Implementation Plan will be revised and updated periodically. Updates will reflect changing market and technical issues and ensure that the priorities remain current, relevant, and important to the industry.

\section{Partnering for a Clean and Competitive Industry of the Future}

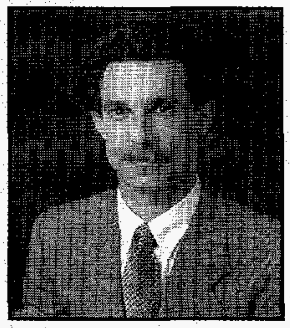

DAN W. Reicher Assistant SeGRETARY ENERGY EFFILIENCY AND RenewABLe ENERGY
Our nation's strength is based in large part on our access to affordable and reliable energy. As we move into the new millennium, our mission is to develop and deploy new ways to meet our energy needs and improve our environmental quality through use of renewable energy and increased energy efficiency.

Through the Industries of the Future Program, the Office of Energy Efficiency and Renewable Energy is actively engaged with U.S. industry to capture energy and natural resources savings by developing and deploying clean and energy efficient technalogies and practices. Working with the nation's most energy

intensive industries, we are mapping a vision of the energy future of American industry and developing the technology needed to implement that vision. This profile describes a few of the many ways that the DOE-industry alliance is working towards a more competitive future for U.S. industry and our nation. 


\section{DISCLAMMER}

This repor was prepared as an account of work sponsored by an agency of the United States Government. Neither the United States Government aor any agency thereof, nor any of their employees, makes any warranty, express or implied, or assumes any legal liability or responsibility for the accuracy, completeress, or usefulness of any information, apparatus, product, or process disclosed, or represents that its use would not infringe privately owned rights. Reference berein to any speciric commercial product, process, or service by trade name, trademark, imanufacturer, or otherwise does not necessarily constitute or imply its endorsement. recommendation, or favoring by the United States Governmeat or any agency thereof. The views and opinions of authors expressed herein do not necessarily state or reflect those of the United States Government or any agency thereof. 


\section{DISCLAIMER}

Portions of this document may be illegible in electronic image products. Images are produced from the best available original document. 


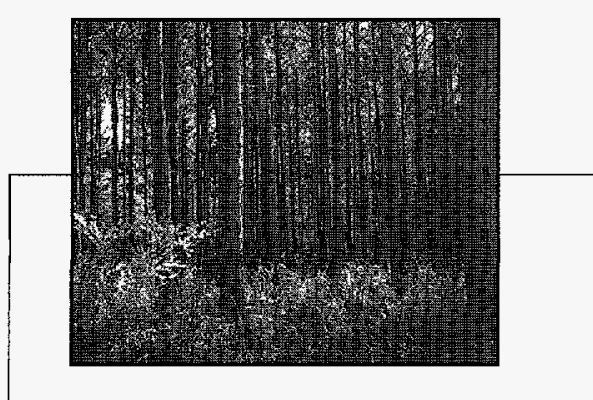

\section{Cooperative Research Areas}

The U.S. forest products industry has endorsed a research agenda that calls for pre-competitive research, development, and demonstration in the following six key technology areas:

\section{Sustainable Forestry}

Increasing forest growth rates and enhancing fiber quality of trees on both highly productive and marginal sites will be key to the future of the U.S. forest products industry. Sustainable forest management integrates goals for wood and paper production with environmental objectives such as conservation of soil, air, and water quality; protection of wildlife and fish habitat; and enhancement of natural aesthetics. The current research pathways include Biotechnology, Basic Physiology of Forest Productivity, Sustainable Soil Productivity, and Remote Sensing to Improve Forest Inventory and Stand Management.

\section{Environmental Performance}

The forest products industry already spends close to $\$ 3$ billion annually on pollution control and is facing large increases in operating and capital costs in order to comply with new environmental regulations. To lower pollution abatement costs, comply with regulations, and ensure that manufacturing facilities are acceptable to industry workers and local communities, the industry must develop and employ advanced pollution prevention technologies. Four research pathways have been developed to address this research area: Improved Margins of Environmental Safety, Process Alternatives Consistent with Pollution Prevention, Treatment Areas, and Environmental Impacts of Sustainable Forestry.

\section{Energi Performance}

Increasing the industry's fuel flexibility and improving process energy efficiency will result in substantial savings for one of the most energy-intensive industries in America. An important area of research is development of new technologies that will allow the industry to become essentially independent of fossil fuels, by self-

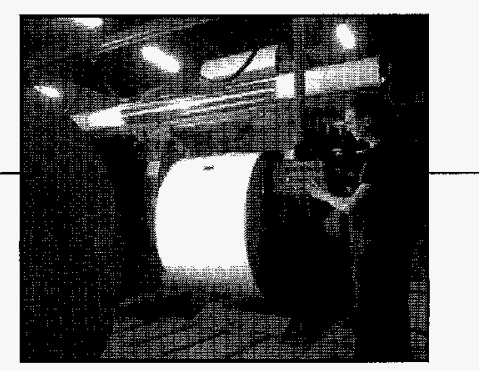

generating all its energy needs from wood residues and biomassderived waste streams. Current research pathways include Fuel Production and Enhancement, Fuel Conversion and Electricity Production, Manufacturing Process Efficiency and Heat Recovery, Environmental Impact of Energy Production and Utilization, and Wider Use of Renewable Resources.

\section{Improved Capital Effectiveness}

The forest products industry spent over $\$ 13$ billion on capital plants and equipment in 1996, almost twice the average among all manufacturing industries. Research leading to reduced capital requirements per unit of production and sales will improve the forest products industry's financial performance, speed the shift to newer technology, and boost its efficiency and responsiveness to evolving customer demands. Current research pathways focus on System and Process Technologies, System Fabrication and Construction, and System Efficiency.

\section{Recycling}

Increased recycling is broadening the industry's raw-material base and increasing profitability. R\&D aimed at lowering costs, improving separation processing technologies, reducing energy usage and fiber deterioration, and determining optimal combinations of virgin and recycled pulps are key to expanding the use of recycled products. Five research pathways have been developed for this research area: Sludge Use and Disposal, Surface Chemistry and Fiber-Fiber Bonding, Sorting and Collection Methodologies and Tools, Improved Separation Technology, and Environmentally Benign Pressure-Sensitive Adhesives.

\section{Sensors and Control}

Advanced sensors and controls can be used to optimize the operation of entire mills or major subsystems, evaluate the structural and performance characteristics of wood in the field, monitor paper quality, detect emissions to ambient air, and function in a host of other situations that improve overall process efficiency and cost effectiveness. The current research and development pathways for this area include Actuators and Control Devices; Process Measurement and Diagnostics; Process and Product Models; Data Presentation, Interpretation, and Human Interface; and Control System Effectiveness.

\section{TAKING ACTION BASED ON INDUSTRY'S VISION}

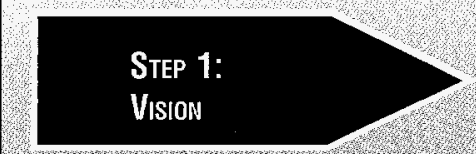

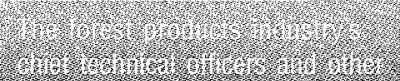
UIt) ant

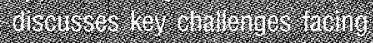

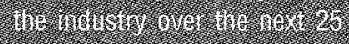

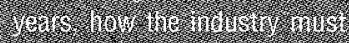

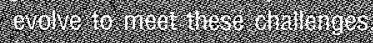
2106.

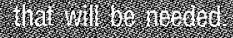
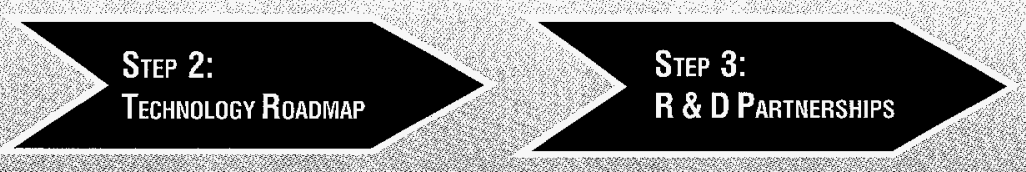

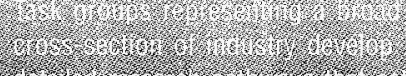

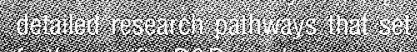

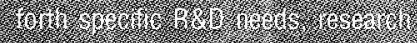

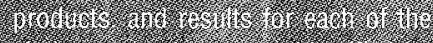

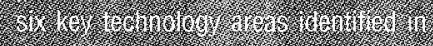
$\operatorname{rin} 60$

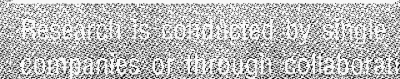

- j.

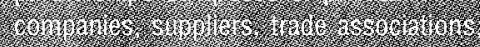

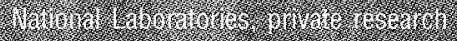

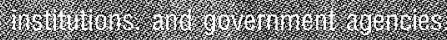




\section{FOREST PRODUCTS INDUSTRY OF THE FUTURE}

\section{Novel Public-Private Partnerships}

The Industries of the Future (IOF) process is driven by industry. Through the vision and technology roadmaps, industry participants set technology priorities, assess the progress of $R \& D$, and ultimately lead the way in using and commercializing the research results. The role of the Office of Industrial Technologies (OIT) is to facilitate the IOF process for the forest products industry. To fulfill this role, OIT encourages industry to undertake long-term sectorwide technology planning and cost-shared research partnerships focused on optimizing the use of energy and materials in operations while reducing waste and pollution.

Through these partnerships, OlT provides streamlined access to the resources and capabilities of the National Laboratories and other Federal programs that share interest with the forest products industry. Supporting this streamlined access is the Laboratory Coordinating Council which helps match unique laboratory capabilities with the technology needs of the forest products industry. Active participation of the Pulp and Paper Education and Research Alliance (comprised of eleven academic institutions) helps to draw the nation's top academic researchers into the Forest Products IOF process.

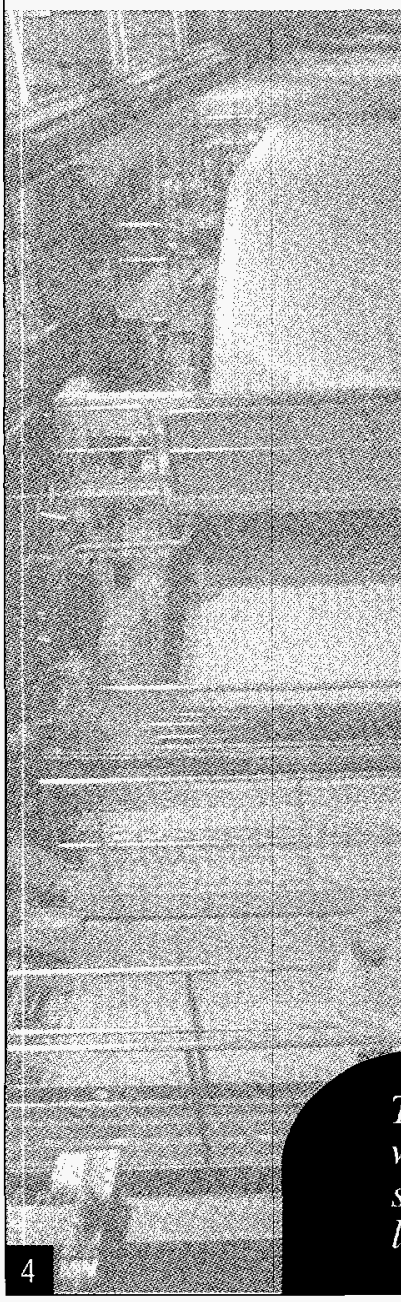

\section{PORTFOLIO HIGHLIGHTS}

\section{Industry of the Future projects advance forest products vision}

The R\&D portfolio of the Forest Products Industries of the Future currently consists of over 50 ongoing projects and 20 completed projects that are co-funded by industry and OIT. By focusing research on the most pressing needs of the industry and requiring a private-sector stake in the research projects, the Industries of the Future process ensures a strategic allocation of resources for technology development.

The following descriptions are a sampling of projects co-funded by the Forest Products IOF or other OIT programs.

\section{Radiofrequency-Induced Pre-extraction of VOCs from Softwood Lumber}

This project will build and test a pilot-scale radiofrequency (RF) pre-treatment unit that extracts and collects volatile organic compounds (VOCs) from lumber before it is sent to a drying kiln. The process simultaneously eliminates the need for VOC controls during wood drying (and the associated carbon dioxide emissions) and recovers a commercial chemical (turpentine).

Partners

$\begin{array}{ll}\text { - Institute of Paper Science } & \text { - Electric Power Research } \\ \text { and Technology } & \text { Institute } \\ \text { - American Kilns, Inc. } & \text { - Southern Co. } \\ \text { - Michigan State University } & \text { - Weyerhaeuser } \\ \text { - Georgia Power } & \text { - Potlatch Corporation } \\ & \text { - Georgia-Pacific Corporation }\end{array}$

\section{Sustainability of High Intensity Forest Management}

To ensure the long-term sustainability of its raw material base, the forest products industry is pursuing increased use of intensively managed tree crops to maximize yield of fiber per harvested tree at the lowest economic and environmental cost. This project is conducting a series of investigations in order to produce guidance 
and tools to help forest land managers maximize biomass

productivity while minimizing impacts to soil and water quality.

\section{Partners}

- Oak Ridge National Laboratory

- Tennessee Valley Authority

- U.S. Forest Service

- Desert Research Institute

- N.C. State University

\section{Novel Chemistry for Wood Pulping}

Through the NICE3 program (see page 7), OIT is helping ChemStone, Inc. to demonstrate a new chemistry that improves the efficiency of wood chip pulping. Trials at operating mills will optimize and validate the benefits of the new pulping process, including lower energy requirements, higher chemical recovery rate, fewer tons of landfilled waste, reduced bleaching requirements, and smaller inputs of virgin wood feedstock.

\section{Partners}

- ChemStone, Inc.

$$
\text { - South Carolina Energy Office }
$$

\section{METHANE de-NOx ${ }^{\circledR}$ Reburning Process for Waste Wood, Sludge, and Biomass-Fired Stoker Boilers}

This project will test the effectiveness of the Institute of Gas Technology's (IGT's) METHANE de-NOX ${ }^{\circledR 3}$ reburn technolagy for overcoming operating problems in biomass-fired stoker boilers. The project will retrofit a $300 \mathrm{MMBtu} / \mathrm{hr}$ waste wood and sludgefired stoker boiler operated by Boise Cascade and test its ability to increase sludge firing rates, increase thermal efficiency, reduce NOx emissions, and reduce natural gas input.

\section{Partners}

- Institute of Gas Technology

- Detroit Stoker Company

- Sargent \& Lundy LLC

$$
\begin{aligned}
& \text { - Babcock \& Wilcox } \\
& \text { - Boise Cascade } \\
& \text { - U.S. Environmental Protection } \\
& \text { Agency }
\end{aligned}
$$

\section{Improved Composite Tubes for Kraft Recovery Boilers}

Boiler tube corrosion reduces kraft recovery boiler energy efficiency and can cause leaks that precipitate dangerous smelt/ water explosions. Through OIT's Advanced Industrial Materials (AIM) program, Oak Ridge National Laboratory is working with a number of project partners to determine the causes of boiler tube corrosion and develop alternative materials and procedures to minimize corrosion-related problems.

\section{Partners}

- Oak Ridge National Laboratory

- 18 pulp and paper companies

- 6 boiler/tube manufacturers

- Institute of Paper Science and Technology

- Pulp and Paper Research Institute of Canada

\section{Case Studies}

\section{Two-Phase VOC Control Project in Kraft Pulp Mills Likely to Reduce Hazardous Emissions}

Several papermaking processes are major sources of volatile organic compounds (VOCs), particularly methanol, which represents 90 percent of the VOC emissions in mills. The forest products industry needs better methods to predict and control these emissions in order to meet environmental regulations for permitting papermaking operations and for controlling hazardous discharges. The Institute of Paper Science and Technology (IPST) has undertaken a two-phased project to develop a better understanding of the behavior of VOCs in mill streams and a method to remove and recover methanol. In Phase I, fundamental measurements will be taken of the liquid-vapor phase in mill streams. A computer model will be developed to simulate the content of VOCs in the streams and predict hazardous emissions, especially when processing changes occur. In Phase II, highperformance, thin-film, composite membranes will be developed to remove and recover VOCs from pulping operations.

\section{Benefits}

- Treats point sources of VOC emissions

- Provides membrane-separation technology that is simple, continuous, and rugged

- Reuses solvents and reduces environmental hazards

- Contributes methods to remove other hazardous air pollutants

\section{Feedstock-to-Product Characterization Tools for the Wood and Pulp Industry Expected to Improve Product Quality, Reduce Waste, and Increase Energy Efficiency}

Tree harvesters need field-mobile tools to determine the physical and chemical characteristics of their feedstock such as the density and moisture content of standing or cut trees, and the carbohydrate and lignin content of trees or wood chips. Pulp and paper mill operators need a rugged technology to monitor and control variations in the manufacturing processes in real time. Researchers from the National Renewable Energy Laboratory and Ames Laboratory are adapting advanced infrared technology to on line sensors that oversee the entire process, from tree selection to final finishing of wood-derived products. A fingerprint of the physical and chemical composition of the feedstock helps to predict the quality of the tinal paper product. This in turn allows feed-forward and feed-backward adjustments during the manufacturing cycle to enhance product quality.

\section{Benefits}

- Improves energy efficiency

- Reduces processing waste

- Lowers production costs

- Enhances product quality 


\section{Case Studies}

\section{High Efficiency Chlorine Dioxide Delignification Process Changes Will Lower Energy Use and Reduce Environmental Impact}

The pulp and paper industry has responded to the stringent environmental regulations placed upon bleaching operations by substituting chlorine dioxide $\left(\mathrm{ClO}_{2}\right)$ for elemental chlorine as the bleaching agent in delignification. Investigators at IPST are using advanced spectroscopic techniques to gain a greater understanding of the fundamental principles of chlorine dioxide delignification with this new method. They have learned that with $\mathrm{ClO}_{2}$, less elemental chlorine is needed to treat pulp and fewer absorbable organically bound chlorides (AOX) are generated in the process. This knowledge will be used to develop processes that require less input of chemicals and energy and that reduce the environmental effect of the bleaching process. This in turn will ensure that the industry conducts its bleaching operations more efficiently and economically.

\section{Benefits}

- Ensures industry's compliance with environmental regulations

- Lowers capital requirements tor bleaching

- Forms AOX with lower chlorine content per carbon atom

- Reduces industry's costs

\section{Marker-Aided Selection Methods for Wood Properties Crucial to Genetic Engineering of Trees for Superior Products}

Trees with certain genetic characteristics are known to improve the quality of pulp, paper, and other wood products manufactured from them. Forestry researchers from two National Laboratories, industry, and academia are working to identify molecular markers associated with superior genotypes in loblolly pine and hybrid poplars in order to select and breed tree stocks with the desirable properties sought by the forest products industry. Using rapid analytical techniques to analyze wood properties, and identifying the quantitative trait loci (QTLs) for each wood property, QTL maps will be constructed and molecular markers associated with each wood property will be identified. This method can be applied to trees of any age, and will give foresters the tools to select and improve future planting stocks for such characteristics as the overall wood density, fiber dimensions, and cellulose and lignin content. These techniques will be valuable in the short-rotation, intensive-culture forestry gaining wide acceptance to meet the industry's demand for wood fiber.

\section{RESEARCH, SERVICES AND RESOURCES}

\section{DOE programs support the Forest Products Industry of the Future}

\section{OIT's Industries of the Future strategy accelerates $R \& D$ of novel technologies of interest to nine energy-intensive industries: aluminum, chemi- cals, forest products, glass, metalcasting, steel, mining, agriculture, and petroleum. The strategy is sponsored and facilitated by OIT, a unit of DOE's Office of Energy Efficiency and Renewable Energy. The focus is on developing high-risk, high-payoff pre-competitive technologies within a 20-year planning time frame.}

As an integral component of the Forest Products Industry of the Future strategy, OIT offers a range of programs that can help forestry, wood, and paper companies begin to save energy, reduce costs, and cut pollution immediately. Using an "integrated delivery" approach, OIT focuses on making an individual company aware of all the potentially applicable technologies, tools, and expertise in OIT's extensive portfolio of cross-cutting products and services, and then providing the right services to meet the customer's needs. Brief summaries of these programs are presented below.

\section{Enabling Technologies}

AIM (Advanced Industrial Materials) develops and commercializes new and improved materials to increase energy efficiency, improve productivity, and enhance material longevity and product quality.

The Combustion program increases productivity, improves energy efficiency, reduces emissions, and enhances fuel flexibility by developing cost-effective and energy-efficient technologies that are necessary for global competitiveness.

Continuous Fiber Ceramic Composite Materials pursues ceramic composite technologies that improve productivity by utilizing higher process temperatures, extending component and system lifetimes, and reducing downtime.

Sensors \& Controls develops and deploys integrated measurement systems for operator-independent control of the manufacturing process. Priority goals are improving technology both in sensors emhedded in hiah-temnerature and other harsh environmental 


\section{Financial Assistance}

The Inventions \& Innovation program provides financial assistance for establishing technical performance and conducting early development of innovative ideas and inventions. Ideas with potential for significant energy savings and commercial use are chosen for financial support through a competitive solicitation process. Technical guidance and commercialization support are offered to successful applicants.

NICE $^{3}$ (National Industrial Competitiveness through Energy, Environment, Economics) is an innovative cost-sharing program that promotes energy efficiency, clean production, and economic competitiveness in industry by providing funding to the state and industry partnerships for technology demonstration projects.

\section{Technical Assistance}

Combined Heat \& Power Challenge is focused on overcoming major barriers that currently exist in implementing combined heat and power systems, including complex and costly environmental permitting, unclear environmental regulations, excessive utility fees and rates, and long and varied Federal tax depreciation schedules.

Compressed Air Challenge is dedicated to improving the efficiency and performance of industrial compressed air systems with the goal of reducing energy use and costs.

IACs (Industrial Assessment Centers) help small, and mediumsized manufacturers identify opportunities to improve productivity, reduce waste, and save energy through comprehensive industrial assessments. Teams of engineering professors and students from 30 universities across the country conduct the assessments and provide recommendations to manufacturers at no cost.

Motor Challenge helps increase the productivity and reliability of electric-motor-driven systems, reduce energy costs, and improve the bottom line by providing reliable, unbiased information, tools, and technical assistance to improve motor system efficiency. As a Motor Challenge Allied Partner, the Technical Association of the Pulp and Paper Industry (TAPPI) helps distribute information products to pulp and paper companies.

Steam Challenge provides informational tools and technical assistance that can help industry enhance productivity, lower production costs, and reduce emissions of its industrial steam systems.

Additional information resources include the following:

IPLocator (www.oit.doe.gov/locator) provides access to information on federally sponsored R\&D projects that are ongoing or recently completed, optimizing the complementary research and development strengths of industry, universities, National Laboratories, and government.

OIT's Resource Catalog, availabie by calling 202-586-2090, describes over 400 publications and other informational products of interest to our customers.

\section{HOW TO GET INVOLVED}

\section{Turning vision into reality}

Industry of the Future partnerships can bring clear competitive advantages to the U.S. forest products industry. Participating companies benefit from reduced cost and risk associated with collaborative research, and they also gain streamlined access to Federal scientific resources. Positioned at the forefront of technology development, these companies reap the benefits of more efficient and productive technologies and, in turn, contribute to our Nation's energy efficiency, industrial competitiveness, and environmental quality.

\section{Ways to participate}

There are many ways to participate in the Forest Products Industry of the Future:

- Monitorour Web pages fornews and announcements of R\&D solicitations, meetinus and cơnferences, and research projects (www.oit.doe.govilor/forest).

- Team withother organizatons and respond to solicitations for cost-shared research issued by OIT's Forest Products Industry of the Future Team, our Enabling Technologies programs and our FinanchalAssistance programs. Information antocoming solicitatorits can be found on the olT home

page.

- Begin savino energy, reducing costs, and cutting pollution in yourplant today by participating in any of the technical assistanceprograms.

- Call Marilyn Burgess, manager of ÖIT's Resource Room $(202-586-2090)$, to learn more about the listed activities and services

- Contact the Laboratory Coordinating Council (LCC) to find out how to work with the National 3 aboratories and what

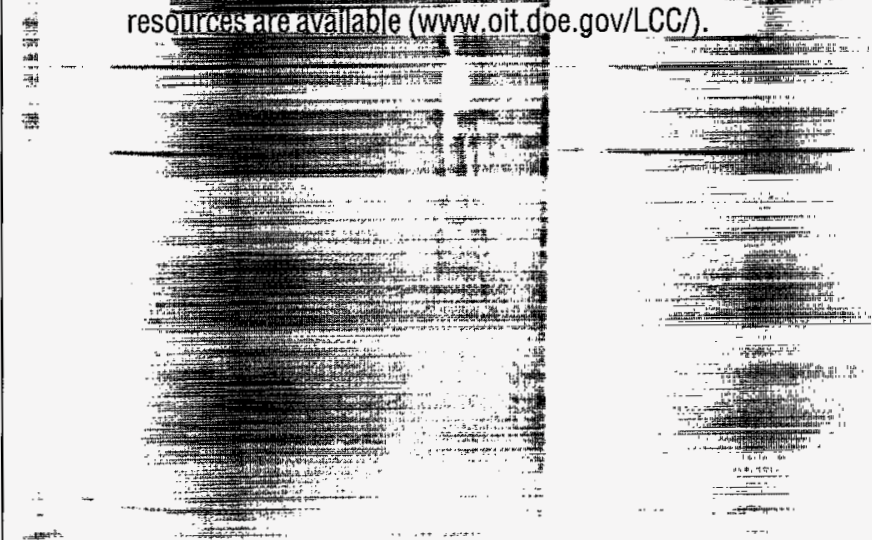

